\title{
INTERDISCIPLINARY BIOMASS BURNING INITIATIVE (POLISH RESEARCH DRAFT)
}

This scientific initiative originating in Poland seeks to link up with activity within the framework of such the International Geosphere-Biosphere Programme (IGBP) Core Projects as the International Global Atmosphere Chemistry Project (IGAC) and the integrated Land Ecosystem- Atmospheric Processes Study (iLEAPS) as well as with the World Meteorological Organization (WMO).

\section{FOREWORD FOR IBBI ${ }^{1}$}

For nearly a year now, preliminary (if wide-ranging) discussions have been underway in Poland within many different scientific circles and teams. The discussions, initiated by the Polish National IGBP Committee, concern the coordination of research into biomass fires in ecosystems, especially forest, scrub and peatlands, and the consequences these have. The project concept encompasses the protection of the atmosphere, hydrosphere and land surface; but also assessment and work to determine the directions to degradative changes in the biosphere. A consequence of the effort has been the emergence of an informal consortium of scientists representing different core disciplines, both pure and applied, who focus on the issues in question and are seeking to ensure a fuller understanding of certain little-studied, highly-complex, processes that govern fires in the biosphere and hinder its sustainable development, including as regards human habitation and existence.

The objective of embarking upon the planned activity within the framework of a domestic and EU project would be to inventory the area of occurrence of wildfires, as well as to assess the influence of human activity in limiting or encouraging the

1 IBBI - Interdisciplinary Biomass Burning Initiative 
onset of fire. The bases of the project emphasise the role of science and technology in the management of natural resources with a view to environmental degradation being limited.

Within the project framework it is planned to use an operating system that will provide for better understanding of the co-dependences involved, as well as for forecasting of the occurrence of fires over different temporal and spatial scales. A particular focus will be on fires involving forests and wetlands, and on the impact of climate change in regard to the wider issue of humankind's adaptation to changing circumstances in central and northern Europe.

While consideration has been given to the submission of an application vis-à-vis the EU's LIFE+ Multiannual Work Programme for the years 2014-2017, this has not in fact proved possible so far, for procedural reasons. A selection of a topic for inclusion within the Programme has been made, however, in respect of adaptation to climate change, and in particular the so-called Priority 1: Climate Change Mitigation.

The most appropriate form would be an international project of the scope: "Undertakings in Poland leading to achievement of the LIFE+ objective as regards sustainable development". The informal aforementioned consortium in existence up to now comprises 6 research groups representative of different scientific institutions and centres in Warsaw and Poznań. These are the PW, UW, IGiK, IBL and WSOP, with the probable coordinator being IBŚRiL Polish Accademy of Sciences.

In line with its highly interdisciplinary nature, the project concept is receiving the strong backing of the Polish National IGBP Global Change Committee PAS, within the framework of the European Environment Change Alliance.

As has been mentioned already, the objective of this project would be to conceive of a programme outline for a system of sustainable development relating to the biosphere (forest and peatland) fire phenomenon from 2015 onwards, in the context of an effort to raise society's awareness, as well as possibilities for controlling this widespread kind of disaster of natural or anthropogenic origin that is of such particular importance to climate protection, nature conservation and human health.

In line with the scientific approaches proposed, attention is drawn to the possibility of this potential threat being assessed, along with its effects for ecosystems from the point of view of their influence on gaseous, particulate and aerosol pollutants in the atmosphere and on human health and the condition of the biosphere, with a possibility to make use of a forecasting spatial model extending to the 2030 time horizon.

The key objective is subordinated to activity seeking to achieve better protection against fires, and effective management from the point of view of the definition of societal wellbeing.

An approach to the achievement of the goals identified has been set out for several of the aforementioned part-categories, with indications given for implementation serving the mitigation of ongoing climate change as predicted and modelled, and suggesting ever-greater variability to the weather in Poland and Europe in the period to 2100, this in turn clearly favouring increasing water stress impacting upon ecosystems. The 
underlying cause is water shortage or water deficit, as well as ever-higher temperatures and more intensive atmospheric dynamics, these all serving to make fires worse. Added to these are anthropogenic factors like arson, changes in land use to include transport routes, the draining of wetlands, pollution, habitat fragmentation and excessive peat exploitation, and factors following on from fires that act to degrade the environment further.

The undertaking of a project of this kind is justified by the need to further perfect the long-term forecasting of climate change. As Kundzewicz (2013) ${ }^{2}$ stresses, in a warmer climate it is necessary to fear an increased incidence of the kind of weather that favours fire, like an extended warm season with heatwaves increasing fire risk, and the area and depth vulnerable to the phenomenon. In almost the entire country the value of the classic index of fire threat - the SSR (Seasonal Severity Rating) will probably increase in the $2071-2100$ period by $40-60 \%$ as compared with the 1961-1990 period (EEA, 2012). Thus every possible combined effort is needed to limit consequences and adjust to the idea that ecosystems need to be safeguarded against the potential cataclysm.

Discussion is ongoing as regards a joint, integrated national research topic linking up with the Europe-wide research network.

\author{
Prof. Matgorzata Gutry-Korycka \\ Polish National IGBP Committee, PAS \\ Future Earth European Alliance member
}

2 Kundzewicz Z.W. 2013, Cieplejszy świat (The Warmer Earth), Wyd. Nauk. PWN, Warsaw and Poznań, 59 pp. 